\title{
Analisis Video Likes To Followers Ratio Instagram Pada 5 Pesepakbola Dengan Followers Terbanyak Di Instagram
}

\author{
I Kade Yudis Aditya Kusuma \\ yudiskusuma64gmail.com
}

\begin{abstract}
Instagram is the top five social media in the world. Instagram users always increase every year. However, many inactive users on Instagram don't use Instagram at all because they may not have an interest in using Instagram. The population in this study were Instagram users in Indonesia with a sample of 198 Instagram users. Users feel the ease of using Instagram social media, and users also feel the benefits of Instagram social media. From the convenience and benefits felt by users, Mina using Instagram social media also produces a very good response. In other words, the ease and benefits obtained are one of the factors in increasing interest in using Instagram social media. Instagram social media can improve and add more varied features to further increase the social interaction of Instagram social media users. The purpose of this study is to calculate the credibility of the Instagram account performance of 5 footballers with the most followers on Instagram. The results of this study indicate that Lionel Messi's account gets the first rank and has good account performance credibility.
\end{abstract}

\begin{abstract}
ABSTRAK
Instagram merupakan top lima media sosial di dunia. Pengguna instagram selalu bertambah tiap tahunnya. Namun banyak pula pengguna tidak aktif instagram sama sekali tidak menggunkan instagram karena kemungkinan tidak memiliki minat untuk menggunakan instagram. Populasi dalam penelitian ini adalah pengguna instagram di Indonesia dengan sampel sebanyak 198 orang pengguna instagram. Pengguna merasakan adanya kemudahan dalam menggunakan media sosial instagram, dan pengguna juga merasakan manfaat pada media sosial instagram. Dari kemudahan dan manfaat yang dirasakan oleh pengguna, maka mina menggunakan media sosial instagram juga menghasilkan respon yang sangat baik. Dengan kata lain kemudahan dan manfaat yang diperoleh salah satu faktor dalam meningkatkan minat mengunakan media sosial instagram. Media sosial instagram dapat meningkatkan dan menambahkan fitur-fitur yang lebih bervariasi agar lebih meningkatkan interaksi sosial pengguna media sosial instagram. Tujuan dari penelitian ini adalah untuk menghitung kredibilitas dari performa akun instagram 5 pesepakbola dengan followers terbanyak di instagram. Hasil dari penelitian ini menujukan bahwa akun Lionel Messi mendapatkan peringkat pertama dan memiliki kredibilitas performa akun yang baik.
\end{abstract}

Keywords : Credibility Account Instagram; Social Media Marketing; Social Media Instagram; Video Likes to Followers Ratio; Pesepakbola Dengan Followers Terbanyak Di Instagram. 


\section{PENDAHULUAN}

Teknologi informasi dan komunikasi yang telah berkembang dengan pesat mampu menghantarkan manusia untuk menciptakan bentuk baru dalam cara berkomunikasi serta berinteraksi melalui media sosial. Media sosial memberikan pengaruh yang cukup besar, saat ini media sosial diajadikan sarana berkomunikasi dalam setiap aktifitas keseharian bersosial di masyarakat. Komunikasi tidak hanya dapat dilakukan secara fisik, tetapi juga dapat dilakukan dengan menggunakan berbagai aplikasi media sosial di dunia maya. Keunggulan layanan aplikasi sosial media adalah memberikan ruang komunikasi dua arah antara konsumenperusahaan dan konsumen-konsumen.

Dengan pesatnya perkembangan teknologi media sosial, telah memberikan dampak terhadap situs-situs komunikasi, dari yang awalnya hanya sekedar email dan chatting, saat ini sudah banyak jejaring media sosial yang bisa digunakan sebagai alat komunikasi. Contoh aplikasi sosial media yang memiliki banyak pengguna saat ini yaitu Instagram. Instagram adalah sebuah aplikasi berbagi foto dan video yang memungkinkan pengguna mengambil foto, mengambil video, menerapkan filter digital, dan membagikannya ke berbagai layanan jejaring sosial, termasuk milik Instagram sendiri. Satu fitur yang unik di Instagram adalah memotong foto menjadi bentuk persegi, sehingga terlihat seperti hasil kamera Kodak Instamatic dan polaroid. Hal ini berbeda dengan rasio aspek 4:3 atau 16:9 yang umum digunakan oleh kamera pada peranti bergerak.

Kehadiran media sosial Instagram dapat membangun sebuah brand, Instagram juga dapat membangun personal branding pemiliknya (Juli 2021). Di Indonesia terdapat 91,77 juta pengguna Instagram yang aktif sehingga menjadikan indonesia sebagai negara dengan pengguna Instagram tersebar disunia. Maraknya jumlah pengguna instagram aktif di Indonesia tentu dapat memberikan peluang bagi brand untuk menjadikan platfrom ini sebagai platfrom social media marketing. Cukup bnyak akun perusahaan-perushaan terkenal yang ada pada Instagram, contohnya seperti pesepakbola. Adapun 5 pesepakbola Dengan Followers Terbanyak Di Instagram, diantaranya yaiu: Marcelo Vieira, James Rodriguez, Neymar Junior, Lionel Messi, Cristiano Ronaldo("5 Pesepakbola Dengan Followers Terbanyak di Instagram Q1-2021 - Selluler.ID”n.d).

Penelitian ini menggunakan metode eksploiratif kuantitatif. Penelitian ini hanya berfokus untuk menghitung kredibilitas Video Likes to Followerws Ratio pada Top 5 Pesepakbola Dengan Followers Terbnyak di Instagram. Tujuan dari penelitian ini adalah mengetahui kredibilitas performa dari akun Instagram 5 Pesepkbola Dengan Followers Terbanyak Instagram.

\section{TINJAUAN PUSTAKA}

Media sosial adalah salah satu dampak yang muncul akibat semakin berkembangnya dunia baru saat ini. Media sosial merupakan media internet yang memungkinkan pengguna dapat mempresentasikan dirinya maupun berinteraksi, bekerja sama, berbagi, berkomunikasi dengan dunia lain dan membentuk ikatan sosial secara virtual (Nasrullah, 2016). Jadi manusia dapat saling terkoneksi di intenet dan membuat sebuah komunitas sosial di dunia maya dan menciptakan medianya untuk lebih memudahkan lagi dalam berinteraksi satu sama lain. 
Berkembangnya media sosial ini tentunya berbanding lurus dengan berkembangnya teknologi komunikasi. Era smartphone menjadi tonggak majunya media sosial. Hal ini dikarenakan semenjak kemunculannya, mulai banyak media sosial yang bermunculan sehingga mempermudah proses komunikasi.

Perkembangan bidang teknologi saat ini terjadi begitu pesat. Melalui perkembangan yang terjadi dari waktu ke waktu menimbulkan maraknya aplikasi - aplikasi serta platform media sosial yang bermunculan. Aplikasi yang sangat diminati oleh masyarakat saat ini diantaranya adalah TikTok, Instagram, Twitter, WhatsApp dan yang lain sebagainya. Seiring berjalannya waktu, aplikasi sosial media tersebut dapat menjadi candu bagi kalangan masyarakat. Tidak hanya kalangan remaja yang menggunakan aplikasi sosial media, orang tua bahkan anak-anak juga aktif menggunakan aplikasi sosial media tersebut.

Tak bisa dimungkiri jika salah satu platform yang paling sering digunakan saat ini adalah Instagram (IG). Keunikan platform ini adalah dapat digunakan untuk kepentingan pribadi, korporasi, maupun sebagai media iklan (adsense) merek dagang tertentu. Lain itu, Instagram juga digukan sebagai penyebar dan sumber informasi untuk kalangan tertentu. Tak heran pemasangan iklan di platform ini baik menggunakan adsense maupun menyewa jasa pendengung (influencer) kian marak.

Instagram merupakan salah satu bentuk hasil dari kemajuan internet dan tergolong salah satu media sosial yang cukup digandrungi oleh khalayak masa kini. Hal ini dapat dibuktikan dengan meningkatnya pengguna instagram pada setiap tahunnya. Terhitung pada April 2017 lalu, Instagram mengumumkan bahwa pengguna aktiv bulanannya telah mencapai kisaran 800 juta akun dan angka tersebut lebih banyak dibandingkan tahun sebelumnya (Yusuf, 2017). Berbeda dengan media sosial lainnya, instagram menitik beratkan kepada postingan foto dan video dari para penggunanya. Keunikan yang membuat instagram satu ini berbeda dengan media sosial pada umumnya. Apalagi, instagram seringkali memperbaharui sistemnya. Sejak kemunculannya pada tahun 2010 silam, instagram sering memperbarui fitur yang ada sehingga fiturnya lebih lengkap dan lebih menarik.

\section{METODE PENELITIAN}

Penelitian ini menggunakan metode ekssploratif kuantitatif untuk mengetahui kredibilitas dari performa akun Instagram 5 Pesepakbola dengan Followers Terbanyak di Instagram. Metode eksploratif merupakan penelitian yang memiliki tujuan untuk melakukan eksplorasi atau memperdalam pengetahuan ataupun ide-ide baru mengenai suatu hal yang baru, guna merumuskan permasalahan secara terperinci.

Tujuan penelitian ini yaitu ingin mengetahui kridibilitas dari performa akun Instagram 5 Pesepakbola dengan Followers Terbanyak di Instagram. Ada beberapa langkah yang harus dilakukan dalam penelitian ini, sehinggga mampu menemukan peringkat. Langkah-langkah yang harus dilakukan pada penelitian ini yaitu : 


\section{Melakukan Eksplorasi Pada Website Untuk Menentukan Objek Yang Dianalisa}

Eksplorasi dilakukan pada website yang menyediakan informasi mengenai objek yang akan dianalisa. Setelah eksplorasi selesai, sehingga menemukan nama-nama pesepakbola yang dijadikan objek analisa. Selanjutnya yaitu memastikan semua pesepakbola tersebut memiliki akun media sosisal yaitu Instagram.

\section{Menghitung Nilai Rata-Rata Variabel Dari 5 Pesepakbola Dengan Followers Terbanyak Di Instagram}

Pada langkah ini, peneliti menghitung nilai variabel video likes dan variabel followers. Variabel merupakan suatu yang memiliki nilai variasi dimana nilai tersebut dapat djadikan sebagai dasar untuk tempat data yang berbeda seperti rasio. Untuk menghitung nilai rata-rata dari variabel video likes dan variabel followers yaitu dengan cara mengambil 10 postingan video terkahir, kemudian dihitung sehingga menemukan nilai rata-rata dari masing-masing variabel.

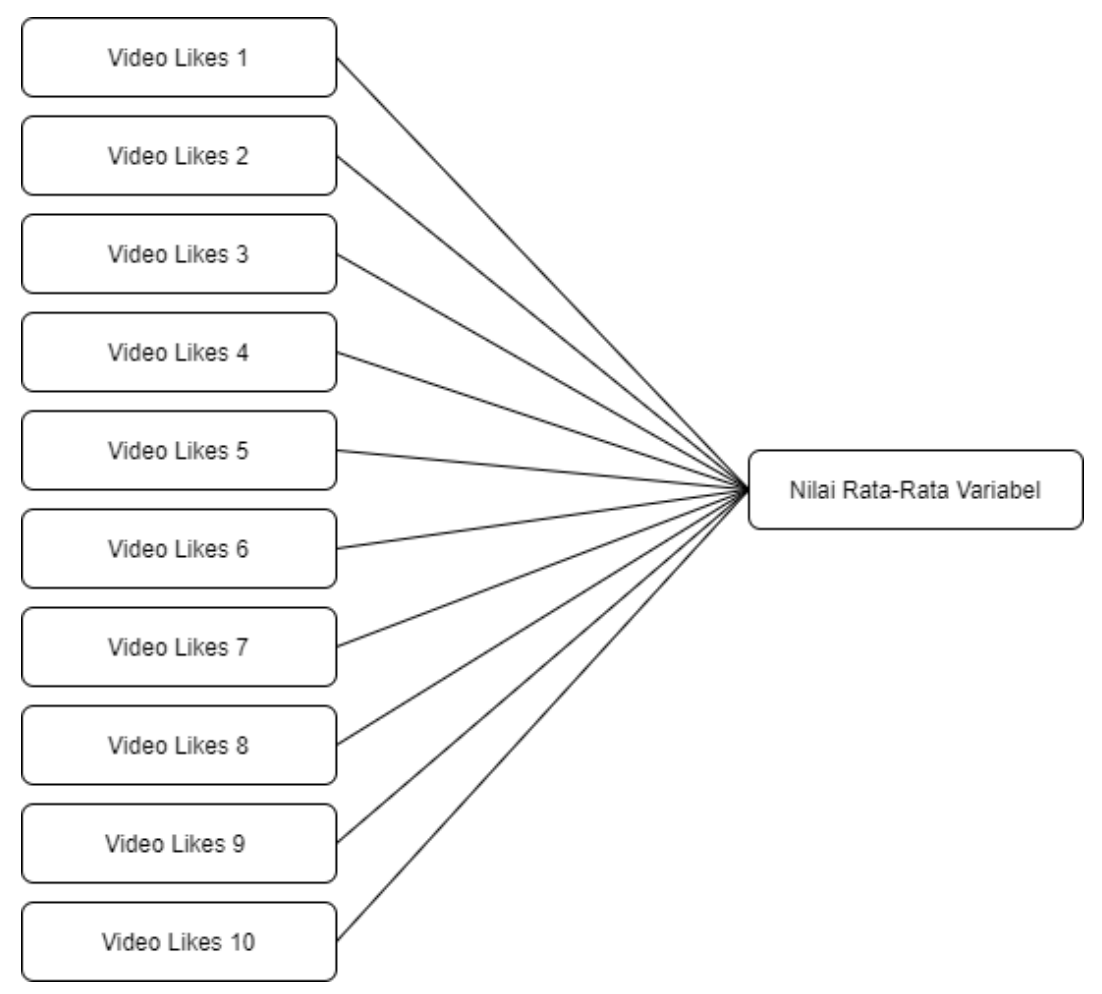

Gambar 1. Analisa Nilai Rata-Rata Variabel.

\section{Menghitung Nilai Kridibilitas Rasio}

Untuk menghitung nilai kridibiltas dari video likes to followers ratio, peneliti menggunakan cara membagi nilai variabel pertama dengan nilai variabel kedua. Jika video likes memiliki nilai 100 dan followers memiliki nilai 300, maka cara menghitungnya yaitu 100:300=0,3. Dengan begitu nilai video likes to followers ratio adalah 0,3 . 


\section{Menentukan Peringkat Pada Akun Instagram}

Pada langkah terakhir yang dilakukan pada penelitian ini yaitu menentukan peringkat pada masing-masing rasio yang ada. Pada penentuan peringkat perlu melihat karakteristik dari rasio yang diteliti. Jika karakteristik rasio merupakan rendah, maka objek yang memiliki nilai rendah akan mendapat peringkat 5 dan objek yang mendapat nilai terttinggi akan mendaptkan peringkat 1 . Namun jika rasio memiliki karakteristik tinggi maka objek yang mendapatkan nilai tinggi akan mendaptkan angka 5 dan objek yang mendaptkan nilai terendah akan mendapatkan angka 1. Setelah mendaptkan hasil kridibilitas ratio maka dapat disimpulkan objek mana yang mendapatkan peringkat 1 sampai dengan peringkat 5 .

\section{HASIL DAN PEMBAHASAN}

Akun Instagram dari 5 Pesepakbola dengan Followers Terbanyak di Instagram, diantaranya :

1. Marcelo Vieira

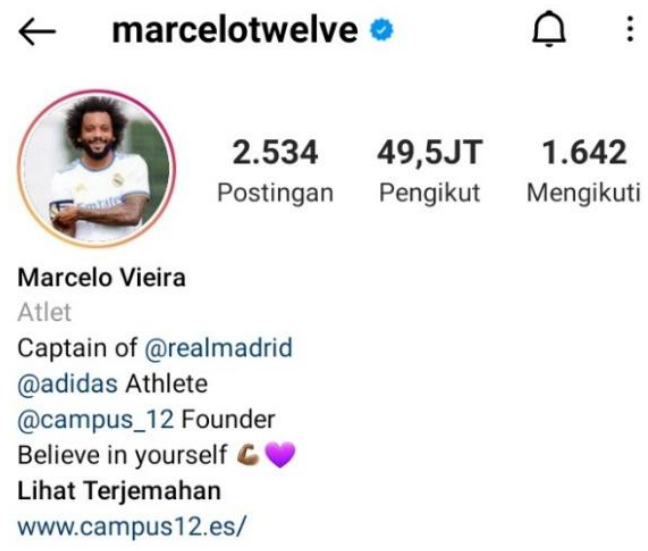

Gambar 1. Akun Instagram Marcelo Vieira

https://instagram.com/marcelotwelve?utm_medium=copy_link

2. Neymar Junior

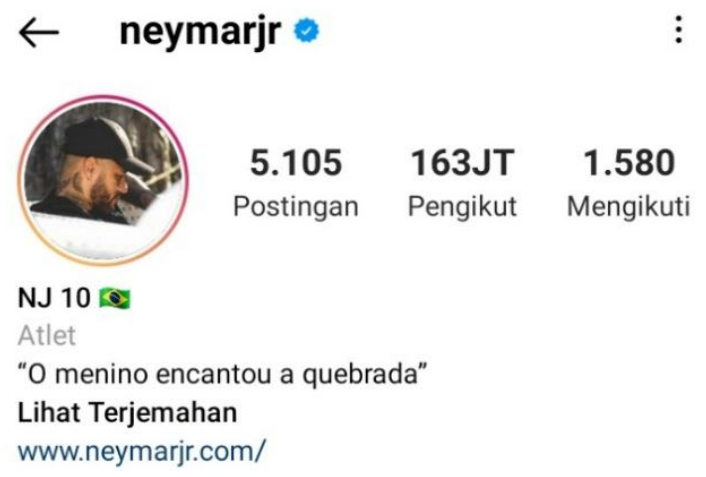

Gambar 2. Akun Instagram Neymar Junior https://instagram.com/neymarjr?utm_medium=copy_link 
3. James Rodriguez

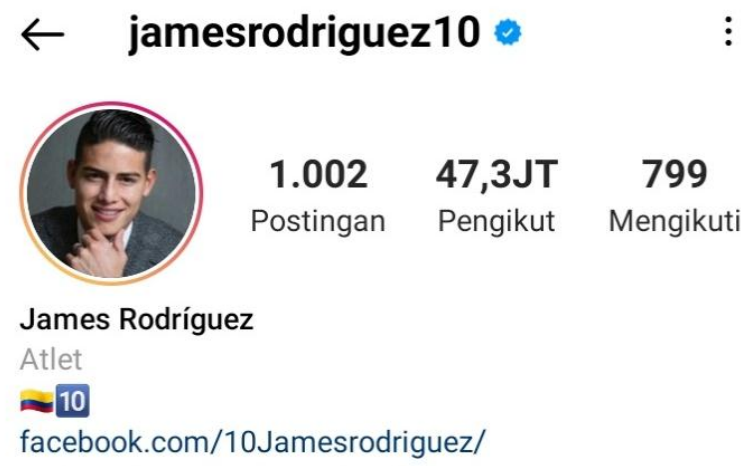

$1.002 \quad 47,3 \mathrm{JT} \quad 799$

Postingan Pengikut Mengikuti

James Rodríguez

Atlet

$\approx 10$

facebook.com/10Jamesrodriguez/

Gambar 3. Akun Instagram James Rodriguez

https://instagram.com/jamesrodriguez10?utm_medium=copy_link

4. Lionel Messi

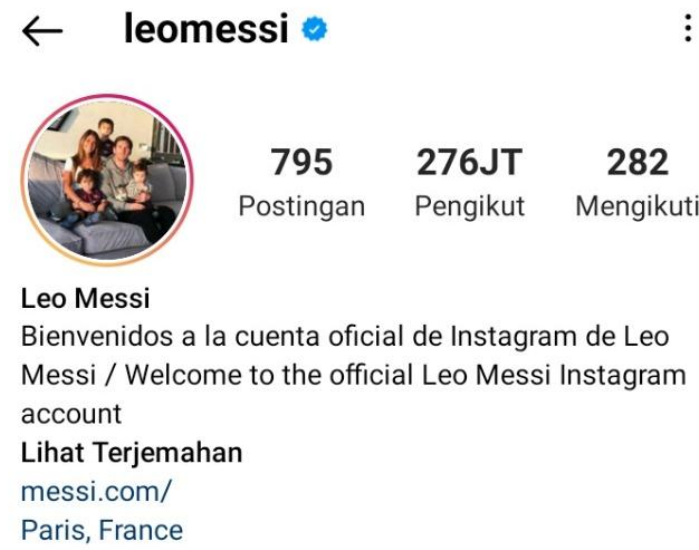

Gambar 4. Instagram Lionel Messi

https://instagram.com/leomessi?utm_medium=copy_link

\section{Cristiano Ronaldo}

$$
\leftarrow \text { cristiano }
$$

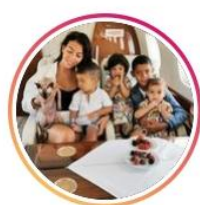

\subsection{9}

Postingan

358JT

486

Cristiano Ronaldo

www.cristianoronaldo.com/

Gambar 5. Akun Instagram Cristiano Ronaldo https://instagram.com/cristiano?utm_medium=copy_link 
Dari kelima akun Instagram 5 Pesepakbola dengan Followers Terbanyak Di Instagram, peneliti menemukan nilai dari masing-masing variabel yang ada untuk menghitung rasio Video Likes to Followers dari setiap akun. Pada akun Instagram terdapat 8 variabel, diantaranya yaitu :

1. Post

2. Followers

3. Following

4. Image Likes

5. Image Comments

6. Video Views

7. Video Likes

8. Video Coments

Dari kedelapan variabel tersebut peneliti hanya fokus untuk menemukan hasil dari 2 variabel, yaitu :

\section{Video Likes}

2. Followers

Dari kedua variabel tersebut kemudian dianalisa sehingga menemukan nilai rata-rata dari variabel video likes dan followers. Untuk menghitung nilai rata-rata dari variabel video likes dan followers yaitu dengan cara mengambil minimal 10 postingan kemudian di hitung sehingga menemukan nilai rata-rata dari masing-masing variabel. Berikut merupakan tabel nilai ratarata dari masing-masing pesepakbola, yaitu :

Tabel 1. Analisa Nilai Rata-Rata Nilai Variabel Video Likes dan Followers Akun Instagram Marcelo Vieira

\begin{tabular}{|c|c|c|}
\hline No & Video Likes & \multirow{2}{*}{ Followers } \\
\hline 1 & 366.910 & \\
\hline 2 & 275.813 & \\
\hline 3 & 193.256 & \\
\hline 4 & 1.065 .987 & \multirow{3}{*}{} \\
\hline 5 & 710.705 & \multirow{2}{*}{49.400 .000} \\
\hline 6 & 217.675 & \\
\hline 7 & 520.246 & \\
\hline 8 & 289.672 & \\
\hline 9 & 551.930 & \\
\hline 10 & 358.741 & \\
\hline Total & $\mathbf{3 2 1 . 3 6 2}$ & \\
\hline & & \\
\hline
\end{tabular}


Tabel 2. Analisa Nilai Rata-Rata Nilai Variabel Video Likes dan Followers Akun Instagram Neymar Junior

\begin{tabular}{|c|c|c|}
\hline No & Video Likes & Followers \\
\hline 1 & 973.319 & \\
\hline 2 & 2.620 .825 & \\
\hline 3 & 1.977 .697 & \\
\hline 4 & 1.214 .317 & \\
\hline 5 & 3.509 .156 & \multirow{2}{*}{162.000 .000} \\
\hline 6 & 4.231 .693 & \\
\hline 7 & 4.261 .042 & \\
\hline 8 & 7.916 .714 & \\
\hline 9 & 5.744 .834 & \\
\hline 10 & 7.121 .694 & \\
\hline Total & $\mathbf{1 . 7 9 7 . 0 7 2}$ & \\
\hline
\end{tabular}

Tabel 3. Analisa Nilai Rata-Rata Nilai Variabel Video Likes dan Followers Akun Instagram James Rodriguez

\begin{tabular}{|c|c|c|}
\hline No & Video Likes & Followers \\
\hline 1 & 133.900 & \\
\hline 2 & 205.539 & \\
\hline 3 & 973.556 & \\
\hline 4 & 604.085 & \\
\hline 5 & 569.732 & \multirow{2}{*}{4} \\
\hline 6 & 919.915 & \\
\hline 7 & 601.891 & \\
\hline 8 & 530.577 & \\
\hline 9 & 297.328 & \\
\hline 10 & 1.347 .636 & \\
\hline Total & $\mathbf{1 6 9 . 7 2 0}$ & \\
\hline
\end{tabular}

Tabel 4. Analisa Nilai Rata-Rata Nilai Variabel Video Likes dan Followers Akun Instagram Lionel Messi

\begin{tabular}{|c|c|c|}
\hline No & Video Likes & Followers \\
\hline 1 & 4.428 .359 & \\
\hline 2 & 3.019 .744 & \\
\hline 3 & 4.590 .777 & \\
\hline 4 & 2.279 .764 & \\
\hline 5 & 2.520 .313 & \multirow{2}{*}{274.000 .000} \\
\hline 6 & 2.338 .402 & \\
\hline 7 & 4.155 .286 & \\
\hline 8 & 11.711 .045 & \\
\hline 9 & 5.130 .006 & \\
\hline 10 & 12.514 .922 & \\
\hline Total & $\mathbf{3 . 7 2 4 . 0 5 2}$ & $\mathbf{2 7 4 . 0 0 0 . 0 0 0}$ \\
\hline
\end{tabular}


Tabel 5. Analisa Nilai Rata-Rata Nilai Variabel Video Likes dan Followers Akun Instagram Cristiano Ronaldo

\begin{tabular}{|c|c|c|}
\hline No & Video Likes & Followers \\
\hline 1 & 1.052 .969 & \multirow{2}{*}{} \\
\hline 2 & 2.462 .972 & \\
\hline 3 & 5.311 .654 & \multirow{2}{*}{35.000 .000} \\
\hline 4 & 4.708 .259 & \\
\hline 5 & 8.965 .436 & \\
\hline 6 & 4.102 .152 & \\
\hline 7 & 4.315 .866 & \\
\hline 8 & 16.172 .469 & \\
\hline 9 & 3.677 .714 & \\
\hline 10 & 9.784 .835 & \\
\hline Total & $\mathbf{1 . 7 5 7 . 9 7 1}$ & $\mathbf{3 5 5 . 0 0 0 . 0 0 0}$ \\
\hline
\end{tabular}

Setelah menghitung nilai rata-rata tersebut, maka akan menemukan hasil akhir nilai rata-rata dari variabel video likes dan followers

Tabel 6. Nilai Variabel Pada Akun Instagram 5 Pesepakbola dengan Followers Terbanyak Di Instagram

\begin{tabular}{|c|c|c|c|c|c|}
\hline Variabel & Marcelo Vieira & Neymar Junior & $\begin{array}{c}\text { James } \\
\text { Rudriguez }\end{array}$ & Lionel Messi & $\begin{array}{c}\text { Cristiano } \\
\text { Ronaldo }\end{array}$ \\
\hline Video Likes & 321.362 & 1.797 .072 & 169.720 & 3.742 .052 & 1.757 .971 \\
\hline Followers & 49.400 .000 & 162.000 .000 & 47.200 .000 & 274.000 .000 & 355.000 .000 \\
\hline
\end{tabular}

Pada akun Instagram terdapat 8 rasio yang relevan digunakan untuk mengukur kredibilitas pada masing-masing akun. Namun pada penelitian kali ini hanya berfokus untuk menghitung Video Likes to Followers Ratio. Untuk menghitung kredibilitas dari masing-masing akun Instagram setiap pesepakbola, peneliti menghitung dengan cara : variabel 1 akan dibagi dengan variabel 2, sehingga ditemukan hasil analisisa dari rasio tersebut.

Tabel 7. Hasil Perhitungan rasio Akun Instagram

\begin{tabular}{|c|c|c|c|c|c|c|}
\hline No & Ratio & Marcelo Vieira & Neymar Junior & $\begin{array}{c}\text { James } \\
\text { Rodriguez }\end{array}$ & Lionel Messi & $\begin{array}{c}\text { Cristiano } \\
\text { Ronaldo }\end{array}$ \\
\hline 1 & $\begin{array}{c}\text { Video Likes } \\
\text { To FFollowers } \\
\text { Ratio }\end{array}$ & 0,006505304 & 0,011093037 & 0,013657124 & 0,003595763 & 0,004952031 \\
\hline
\end{tabular}

Video Likes to Followers Views Ratio memiliki karakteristik yang tinggi, artinya semakin tinggi nilai yang dihasilkan maka semakin baik kredibilitas dari performa akun tersebut. Untuk 
memberikan peringkat pada masing-masing Pesepakbola, peneliti memberikan angka 5 kepada pesepakbola yang mendapatkan nilai tertinggi dan angka 1 untuk pesepkabola yang mendapatkan nilai terendah. Berikut merupakan tabel urutan nilai yang dihasilkan oleh masingmasing pesepakbola.

Tabel 8. Nilai Rasio Akun Instagram 5 Pesepakbola Dengan Followers Terbanyak Di Instagram

\begin{tabular}{|c|c|c|c|c|c|}
\hline Ratio & Marcelo Vieira & Neymar Junior & James Rodrigue & Lionel Messi & $\begin{array}{c}\text { Cristiano } \\
\text { Ronaldo }\end{array}$ \\
\hline $\begin{array}{c}\text { Video Likes To } \\
\text { Followers Ratio }\end{array}$ & 3 & 2 & 1 & 5 & 4 \\
\hline
\end{tabular}

Dari Tabel Nilai Rasio Akun Instagram 5 Psepakbola dengan Followers Terbanyak Di Instagram dapat simpulkan bahwa akun Lionel Messi mendapatkan nilai tertinggi untuk rasio Video Likes to Followers. Sedangkan akun James Rodriguez mendapatkan nilai terendah untuk rasio ini. Jadi, pada penelitian ini akun Lionel Messi memiliki kredibilitas performa yang lebih baik dibandingkan dengan pesepakbola yang lainnya.

\section{KESIMPULAN}

Tujuan dari penelitian ini adalah mengetahui kridibilitas performa dari akun Instagram 5 Pesepakbola Dengan Followers Terbanyak Di Instagram menggunakan Video Likes to Followers Ratio. 5 Pesepakbola tersebut adalah : Marcelo Vieira, James Rodriguez, Neymar Junior, Lionel Messi dan Crisitano Ronaldo. Dari kelima pesepakbola tersebut dapat disimpulkan bahwa :

1. Peringkat pertama diraih oleh James Rodriguez dengan nilai 0,013657124

2. Peringkat kedua Neymar Junior dengan nilai 0,011093037

3. Peringkat ketiga Marcelo Vieira dengan nilai 0,006505304

4. Peringkat keempat Cristiano Ronaldo dengan nilai 0,004952031

5. Peringkat kelima Lionel Messi dengan nilai 0,003595763 


\section{DAFTAR PUSTAKA}

https://repository.unair.ac.id/83155/1/abstrak.pdf

file://C:/Users/ASUS\%20A46C/Downloads/16.04.008_abstraksi.pdf

https://www.kompas.com/tren/read/2021/10/06/100500365/sejarah-instagram-dan-ceritaawal-peluncurannya?page=all

https://id.wikipedia.org/wiki/Instagram

https://accesstrade.co.id/sejarah-instagram-1546

https://www.liputan6.com/tekno/read/3906736/instagram-adalah-platform-berbagi-foto-danvideo-ini-deretan-fitur-canggihnya

https://www.cekaja.com/info/mengulik-sejarah-instagram

https://www.instagram.com/cristiano/

https://www.instagram.com/leomessi/

https://www.instagram.com/marcelotwelve/?hl=id

https://www.instagram.com/neymarjr/

https://www.instagram.com/jamesrodriguez10/ 